\title{
The new fifth-generation cephalosporins - a balance between safety and efficacy
}

\author{
Aura RUSU1 ${ }^{1}$, loana-Andreea LUNGU² \\ ${ }^{1}$ Pharmaceutical and Therapeutical Chemistry Department, Faculty of Pharmacy, \\ "George Emil Palade" University of Medicine, Pharmacy, Science and Technology, Targu Mures, Romania \\ ${ }^{2}$ Doctoral School of Medicine and Pharmacy, "George Emil Palade" University of Medicine, \\ Pharmacy, Science and Technology, Targu Mures, Romania
}

\begin{abstract}
Cephalosporins are beta-lactam antibiotics classified into five generations. The newest generation has three representatives: ceftaroline fosamile, the combination ceftolozane/tazobactam (cephalosporin/beta-lactamase inhibitor), and ceftobiprole medocaril. These new cephalosporins are valuable anti-infective agents, with potent activity against multidrug-resistant bacteria, and with a positive balance between benefits and side effects. However, the fifth-generation cephalosporins should be judiciously used to prevent the occurrence of bacterial resistance phenomenon.
\end{abstract}

Keywords: cephalosporins, ceftaroline, ceftolozane, ceftobiprole, MRSA, community-acquired pneumonia, complicated skin and soft tissue infections

\section{INTRODUCTION}

Cephalosporins (CFs) are betalactam antibiotics with numerous representatives widely used in the therapy of infectious diseases. Like other beta-lactam antibiotics, CFs inhibit the synthesis of the bacterial cell wall. The beta-lactam ring is essential in binding to the penicillin-binding proteins, crucial enzymes in the synthesis of the bacterial cell wall. The high affinity of fifth-generation CFs for penicillin-binding proteins leads to an efficient activity against clinically relevant pathogens. The new CFs (fourth and fifth generations) have emerged as a result of increased bacterial resistance to classical antibiotics. Based on the antimicrobial activity, the CFs are classified into five generations (Table 1) [1]. Representatives of the fifth-generation which are used in therapy are comprised of: ceftaroline fosamil, ceftolozane/ tazobactam, and ceftobiprole medocaril [1-3]. The clinical studies conducted so far support the positive balance between benefits and side effects for these new CFs. However, the fifth-generation CFs should be judiciously used in difficult-to-treat bacterial infections only, in the situation where other antibacterial drugs were not efficient.

\section{REPRESENTATIVES}

\section{Ceftaroline fosamil}

Ceftaroline fosamil (anatomical therapeutic chemical (ATC) code: J01DI02) is a relatively recent approved cephalosporin from the fifth-generation $[1,4,5]$. The U.S. Food and Drug Administration approved ceftaroline fosamil in 2010 and the European Medicine Agency, in 2011 (under trade name Teflaro and Zinforo) [5-7].

Ceftaroline fosamil is active against 
Gram-positive (G(+)) organisms, including methicillin-resistant Staphylococcus aureus (MRSA) and Streptococcus pneumoniae, as well as common Gram-negative (G(-)) organisms [6].

\section{Physical-chemical properties.}

Ceftaroline is an oxyimino compound based on the structure of cefozopran (a fourth-generation representative) [6]. Ceftaroline fosamil is a prodrug that turns in vivo into ceftaroline (the active metabolite). The name "fosamil" is given by an extra phosphono group in the chemical structure comparative to ceftaroline. The resulted compound has the advantage that it is more watersoluble [6]. The oxime group in the C7 acyl moiety and a 1,3-thiazole ring attached to the central nucleus (C3 position) facilitate the increased activity against MRSA (Table 2 ) $[6,8]$. The parenteral formulation (600 mg powder for concentrate for solution for infusion) contains an equivalent amount of ceftoraline fosamil acetic acid solvate monohydrate [5].

\section{Indications, dosing and} administration. Ceftaroline fosamil has been approved for administration to children (neonates, infants, children, adolescents) for the same indications as for adults: complicated skin and soft tissue infections and community-acquired pneumonia [5]. Ceftaroline fosamil is administrated intravenously (600 mg every 12 hours over 1 hour in adults) during 5-14 days. Dosage adjustment is necessary for patients with moderate to severe renal impairment [6]. Also, ceftaroline fosamil is used off-label in the treatment of bacteremia, endocarditis, osteoarticular infections, hospital-acquired pneumonia, and meningitis [9].
Safety of ceftaroline fosamil. Ceftaroline fosamil is considered effective in therapy, and welltolerated, with a good safety profile. However, ceftaroline fosamil could be responsible for diarrhea, nausea, headache and pruritus as the most common side effects with similar rates compared to other antibiotics [5,6,9-11]. Precautions for use and special warnings are for hypersensitivity reactions, Clostridium difficileassociated diarrhea, superinfections with non-susceptible bacteria, and pre-existing seizure disorder. Ceftaroline fosamil has a low potential for drug-drug interactions $[6,12]$. Because the effects of the compound in pregnancy and lactation or on fertility are unknown, it is advisable to avoid the treatment in these situations [5]. More studies are needed in the future to assess the safety profile of ceftaroline fosamil [9].

\section{Ceftolozane/tazobactam combination}

Ceftolozane is a new fifthgeneration $\mathrm{CF}$, a derivative of ceftazidime (third generation). Because it is not resistant to beta-lactamases, ceftolozane was combined with an inhibitor of beta-lactamases, respectively tazobactam. The obtained combination provides great activity against extended-spectrum betalactamase-producing Enterobacteriaceae, Pseudomonas aeruginosa, and certain anaerobic germs $[2,13]$. The combination of ceftolozane with tazobactam (ATC code: J01DI54) was approved in 2014 by the FDA, and in 2015 by the EMA (under trade name Zerbaxa). Recently, the FDA has approved Zerbaxa for the treatment of adults with hospital-acquired and ventilator-associated bacterial pneumonia [14-16]. 
TABLE 1. Classification of the most used CFs by generation and route of administration $(G(+)=$ Gram positive, $G(-)=G r a m$ negative $)$ $[1,2,17,22,24]$.

\begin{tabular}{|c|c|c|c|c|c|c|c|c|c|}
\hline \multicolumn{10}{|c|}{ Generations/Administration } \\
\hline \multicolumn{2}{|c|}{ First } & \multicolumn{2}{|c|}{ Second } & \multicolumn{2}{|c|}{ Third } & \multicolumn{2}{|c|}{ Fourth } & \multicolumn{2}{|l|}{ Fifth } \\
\hline Cefalotine & parenteral & Cefamandol & parenteral & Cefotaxime & parenteral & Cefpirome & parenteral & Ceftaroline fosamil & parenteral \\
\hline Cefapirine & parenteral & Cefuroxime & parenteral & Ceftazidime & parenteral & Cefepime & parenteral & $\begin{array}{c}\text { Ceftolozane/ } \\
\text { tazobactam }\end{array}$ & parenteral \\
\hline Cefalexina & oral & Cefoxitin & parenteral & Ceftriaxone & parenteral & & & Ceftobiprol medocaril & parenteral \\
\hline Cefadroxil & oral & Cefotetan & parenteral & Cefoperazone & parenteral & & & & \\
\hline Cefatrizine & oral & Cefaclor & oral & Flomoxef & parenteral & & & & \\
\hline \multirow[t]{2}{*}{ Cefradine } & oral & Cefprozil & oral & Cefixime & oral & & & & \\
\hline & & $\begin{array}{c}\text { Cefuroxime } \\
\text { axetil }\end{array}$ & oral & Ceftibuten & oral & & & & \\
\hline \multicolumn{10}{|c|}{ Antibacterial spectrum } \\
\hline \multicolumn{2}{|c|}{$\begin{array}{l}\mathrm{G}(+) \text { cocci } \\
\text { (staphylococci spp. and } \\
\text { streptococci spp.) } \\
\text { All have minimal } \\
\text { activity against } \mathrm{G}(-) \\
\text { bacteria. }\end{array}$} & \multicolumn{2}{|c|}{$\begin{array}{l}\text { All have less activity } \\
\text { against G(+) cocci } \\
\text { and increased activity } \\
\text { against G(-) bacilli } \\
\text { compared to the first- } \\
\text { generation. Cefuroxime } \\
\text { has increased activity } \\
\text { against Haemophilus } \\
\text { influenza. Cefotetan } \\
\text { and cefoxitin have } \\
\text { increased activity } \\
\text { against Bacteroides spp. }\end{array}$} & \multicolumn{2}{|c|}{$\begin{array}{l}\text { All have extended activity } \\
\text { against G(-) bacteria } \\
\text { (including those resistant } \\
\text { to the first and second } \\
\text { generation CFs or other } \\
\text { beta-lactam antibiotics). } \\
\text { Ceftriaxone is useful } \\
\text { in the treatment of } \\
\text { meningitis (caused by } \\
\text { Haemophilus influenza, } \\
\text { Neisseria meningitidis, } \\
\text { or Streptococcus } \\
\text { pneumoniae) gonorrhea } \\
\text { and disseminated Lyme } \\
\text { disease. Ceftazidime } \\
\text { presents activity } \\
\text { against Pseudomonas } \\
\text { aeruginosa. }\end{array}$} & \multicolumn{2}{|c|}{$\begin{array}{l}\text { Cefepime is active } \\
\text { against Streptococcus } \\
\text { pneumoniae, } \\
\text { methicillin-resistant } \\
\text { Staphylococcus } \\
\text { aureus (MRSA), } \\
\text { and Pseudomonas } \\
\text { aeruginosa. In } \\
\text { addition to the } \\
\text { activity of the third } \\
\text { generation, cefepime } \\
\text { has activity against } \\
\text { beta-lactamase- } \\
\text { producing G(-) bacilli. }\end{array}$} & \multicolumn{2}{|c|}{$\begin{array}{l}\text { Ceftaroline is a broad- } \\
\text { spectrum antibiotic with great } \\
\text { activity against MRSA, Listeria } \\
\text { monocytogenes, Enterococcus } \\
\text { faecalis, and no activity against } \\
\text { Pseudomonas aeruginosa. } \\
\text { Ceftolozane/tazobactam } \\
\text { has activity against resistant } \\
\text { G(-) pathogens (including } \\
\text { Pseudomonas aeruginosa), } \\
\text { Enterobacteriaceae, and } \\
\text { some anaerobic pathogens } \\
\text { (e.g., Bacteroides fragilis). } \\
\text { Ceftobiprole is active against } \\
\text { MRSA and Streptococcus } \\
\text { pneumoniae resistant to third- } \\
\text { generation CFs and penicillin, } \\
\text { and G(-) bacteria associated with } \\
\text { hospital-acquired pneumonia and } \\
\text { community-acquired pneumonia. }\end{array}$} \\
\hline
\end{tabular}

Physical-chemical properties. The chemical structure is based on the structure of ceftazidime (an oxyimino-aminothiazolyl CF), optimized to have activity on Pseudomonas spp. The aminothiadiazole moiety (attached to the side-chain from C7 position) confers increased activity against $\mathrm{G}(-)$ bacteria. Also, a pyrazole moiety attached to the side-chain from C3 position confers stability to beta-lactamases and permeability through the outer bacterial membrane. These properties of ceftolozane lead to increased activity against Pseudomonas aeruginosa. The parenteral formulation (1 g ceftolozane/0.5 g tazobactam powder for concentrate for solution for infusion) contains an equivalent amount of ceftolozane sulphate and tazobactam sodium) [15].

\section{Indications, dosing and}

administration. Usually, the approved dose of ceftolozane/ tazobactam is $1 \mathrm{~g}$ ceftolozane/0.5 g tazobactam for the treatment of complicated intra-abdominal infections, urinary tract infections and acute pyelonephritis. Hospitalacquired pneumonia, including ventilator-associated pneumonia, require a dose of $2 \mathrm{~g}$ ceftolozane/ 1 g tazobactam. It is administered intravenously, every 8 hours (1 hour infusion time) for 4- 14 days. It can be associated with metronidazole and other antibacterial agents for a broader antimicrobial spectrum $[15,19]$.

\section{Safety of ceftolozane/}

tazobactame. Generally, therapy with ceftolozane/tazobactam is well tolerated. The reported common side effects such as nausea, vomiting, diarrhea, constipation, abdominal pain, hypotension, rash, headache, dizziness, insomnia, anxiety, hypokalemia, thrombocytosis, and Clostridioides difficile colitis were mild or moderate $[16,20]$. Although contraindications for the use of ceftolozane/tazobactam have not been identified, precautions for use and special warnings are hypersensitivity reactions (may appear in patients allergic to beta-lactam antibiotics) and impairment of renal function [15]. In ceftolozane/tazobactam administration, no significant 
a)<smiles>CCO/N=C(\C(=O)N[C@@H]1C(=O)N2C(C(=O)[O-])=C(Sc3nc(-c4cc[n+](C)cc4)cs3)CS[C@H]12)c1nsc(NP(=O)(O)O)n1</smiles>

b)<smiles>Cn1c(N)c(NC(=O)NCCN)c[n+]1CC1=C(C(=O)O[Na])N2C(=O)[C@H](NC(=O)/C(=N\OC(C)(C)C(=O)O)c3nsc(N)n3)[C@H]2SC1</smiles><smiles>CC1(Cn2ccnn2)C(C(=O)O)N2C(=O)CC2S1(=O)=O</smiles>

c)

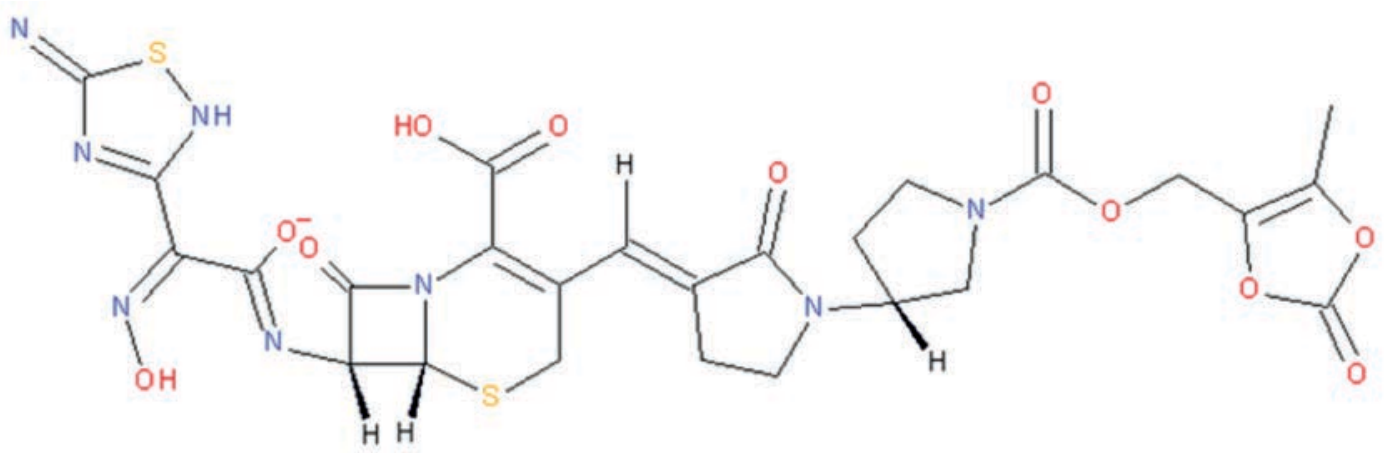

FIGURE 1. Chemical structures of a) ceftaroline fosamil; b) ceftolozane/tazobactam; c) ceftobiprole medocaril [18]

drug-drug or food-drug interactions have been reported. There is no data on ceftolozane/tazobactam effects in pregnancy, breastfeeding, or on fertility $[15,20]$. Unlike ceftaroline fosamil, ceftolozane/ tazobactam combination is under evaluation for use in children [21].

\section{Ceftobiprole medocaril}

Ceftobiprole medocaril (ATC code: J01DI) is the prodrug form of ceftobiprole [22,23]. This fifthgeneration cephalosporin has been licensed in some European and non-European countries (Zeftera or Zevtera). However, ceftobiprole has not been approved by the FDA and EMA $[22,24]$. Ceftobiprole presents activity against MRSA,

Streptococcus

pneumoniae resistant to thirdgeneration CFs and penicillin, and G(-) bacteria associated with hospital-acquired pneumonia and community-acquired pneumonia $[3,22,25]$.
Physical-chemical properties.

Structurally, this new cephalosporin is an yrrolidinone-3-ylidenemethyl cephem [24]. The used pharmaceutical form is a watersoluble monosodium salt $[23,24]$.

\section{Indications, dosing and} administration. Ceftobiprole medocaril is indicated for the treatment of complicated skin and soft tissue infections and pneumonia [24]. Ceftobiprole medocaril is administrated 
intravenously (500 mg every 8 hours over 2 hours in adults) during 4 - 14 days. Dosage adjustment is necessary for patients with moderate and severe renal impairment [23].

\section{Safety of ceftobiprole medocaril.}

Ceftobiprole has a good safety profile [3]. Nausea, headache and gastrointestinal disorders are the most common side effects of ceftobiprole $[3,22]$. Besides the broad spectrum of activity (including MRSA), the excellent safety profile of ceftobiprole medocaril is a significant advantage in comparison with other antimicrobial agents. However, there are no published studies regarding the usage of ceftobiprole medocaril in pregnancy, breastfeeding, effects on fertility, and drug-drug interactions [23]. The ongoing phase 3 studies will contribute to the list of approved indications and will complete the knowledge on the use of ceftobiprole medocaril [3].

\section{CONCLUSIONS}

Ceftaroline fosamile, the combination ceftolozane/ tazobactame, and ceftobiprole medocaril are the first representatives of the fifthgeneration of CFs used in therapy. These new antibiotics are valuable anti-infective agents with a positive balance between benefits and side-effects. Nevertheless, the fifth-generation CFs should be highly restricted to prevent the occurrence of bacterial resistance. These new beta-lactam antibiotics must be judiciously used, only in the situation where other antibacterial drugs were not effective.

Conflict of interest: none declared Financial support: none declared

\section{REFERENCES}

1. Bui T, Preuss CV. Cephalosporins. [Updated 2020 Mar 24]. In: StatPearls [Internet]. Treasure Island (FL): StatPearls Publishing; 2020 Jan-. Available from: https://www. ncbi.nlm.nih.gov/books/NBK551517/ (Accessed 08/27/2020).

2. Cho JC, Fiorenza MA, Estrada SJ. Ceftolozane/Tazobactam: A Novel Cephalosporin/ $\beta$-Lactamase Inhibitor Combination. Pharmacotherapy 2015; 35(7):701-715.

3. Giacobbe DR, Rosa FGD, Bono VD et al. Ceftobiprole: Drug Evaluation and Place in Therapy. Expert Review of Anti-infective Therapy 2019;17(9):689-698.

4. Duplessis C, Crum-Cianflone NF. Ceftaroline: A New Cephalosporin with Activity against Methicillin-Resistant Staphylococcus Aureus (MRSA). Clin Med Rev Ther. 2011;3.

5. Zinforo, European Medicines Agency, [Online]. Available: https://www.ema. europa.eu/en/medicines/human/EPAR/ zinforo (Accessed 08/27/2020).

6. Laudano JB. Ceftaroline Fosamil: A New Broad-Spectrum Cephalosporin. J.
Antimicrob. Chemother. 2011; 66(3):iii11-iii18.

7. Drug Approval Package: Teflaro (ceftaroline fosamil) NDA \#200327 https://www. accessdata.fda.gov/drugsatfda_docs/ nda/2010/200327orig1s000toc.cfm (Accessed 09/01/2020).

8. Ceftaroline fosamil, PubChem, [Online]. Available: https://pubchem.ncbi.nlm.nih. gov/compound/9852981 (Accessed 09/01/2020)

Pani A, Colombo F, Agnelli F et al. Off-Label Use of Ceftaroline Fosamil: A Systematic Review. Int. J. Antimicrob. Ag. 2019; 54(5):562-571.

9. Rosanova MT, Aguilar PS, Sberna $\mathrm{N}$ et al. Efficacy and Safety of Ceftaroline: Systematic Review and Meta-Analysis. Ther Adv Infect Dis. 2018;6.

10. Cheng K, Pypstra R, Yan JL et al. Summary of the Safety and Tolerability of Two Treatment Regimens of Ceftaroline Fosamil: $600 \mathrm{Mg}$ Every $8 \mathrm{~h}$ versus $600 \mathrm{Mg}$ Every $12 \mathrm{~h}$.

J. Antimicrob Chemother. 2019; 74(4):1086-1091.
11. Teflaro, FDA, [Online]. Available at: https:// www.accessdata.fda.gov/drugsatfda_docs/ label/2011/200327s001lbl.pdf (Accessed 09/04/2020).

12. Xipell M, Paredes S, Fresco L et al. Clinical Experience with Ceftolozane/Tazobactam in Patients with Serious Infections Due to Resistant Pseudomonas Aeruginosa. J Glob Antimicrob Re. 2018;13:165-170.

13.Zerbaxa, FDA, [Online]. Available at: https:// www.accessdata.fda.gov/drugsatfda_docs/ label/2014/206829lbl.pdf (Accessed 09/02/2020).

14. Zerbaxa, European Medicines Agency, [Online]. Available at: https://www.ema. europa.eu/en/medicines/human/EPAR/ zerbaxa (Accessed 09/02/2020).

15. FDA, FDA approves new treatment for hospital-acquired and ventilator-associated bacterial pneumonia, [Online]. Available at: https://www.fda.gov/news-events/ press-announcements/fda-approves-newtreatment-hospital-acquired-and-ventilatorassociated-bacterial-pneumonia (Accessed 09/03/2020). 
16. Cephalosporins - Infectious Diseases, Merck Manuals Professional Edition, [Online]. Available: https://www. merckmanuals.com/professional/ infectious-diseases/bacteria-andantibacterial-drugs/cephalosporins. (Accessed 09/03/2020).

17. PubChem, [Online]. Available at: https:// pubchem.ncbi.nlm.nih.gov/ (Accessed 09/03/2020).

18. Solomkin J, Hershberger E, Miller B et al. Ceftolozane/Tazobactam Plus Metronidazole for Complicated IntraAbdominal Infections in an Era of Multidrug Resistance: Results From a
Randomized, Double-Blind, Phase 3 Trial (ASPECT-CIAI). Clin Infect Dis. 2015; 60(10):1462-1471.

19. Sorbera M, Chung E, Ho CW et al. Ceftolozane/Tazobactam: A New Option in the Treatment of Complicated GramNegative Infections. P\&T. 2014; 39(12):825-832.

20. Bradley JS, Ang JY, Arrieta AC et al. Pharmacokinetics and Safety of Single Intravenous Doses of Ceftolozane/ Tazobactam in Children With Proven or Suspected Gram-Negative Infection. Pediatr Infect Dis J. 2018;37(11):1130-1136.

21. Liapikou A, Cillóniz C, Torres A. Ceftobiprole for the Treatment of
Pneumonia: A European Perspective. Drug Des Devel Ther. 2015;9:4565-4572.

22. Zevtera - Product monograph, AVIR Pharma Inc., 2017. [Online]. Available at: AVIR Pharma Inc. https://www.avirpharma. com/pdf/Product-Monograph-Zevtera.pdf (Accessed 09/13/2020).

23. Chahine EB, Nornoo AO. Ceftobiprole: The First Broad-Spectrum Anti-MethicillinResistant Staphylococcus Aureus Beta-Lactam. Journal of Experimental \& Clinical Medicine 2011;3(1):9-16.

24. Grau S. Safety and Tolerability of Ceftobiprole. Rev Esp Quimioter. 2019; 32(3):34-36. 